ISSN 2075-4450

www.mdpi.com/journal/insects/

Correction

\title{
Correction: Lubanga, U.K., et al. Semiochemical and Vibrational Cues and Signals Mediating Mate Finding and Courtship in Psylloidea (Hemiptera): A Synthesis. Insects 2014, 5, 577-595.
}

\author{
Umar K. Lubanga ${ }^{1, *}$, Christelle Guédot ${ }^{2}$, Diana M. Percy ${ }^{3}$ and Martin J. Steinbauer ${ }^{1}$ \\ 1 Department of Ecology, Environment \& Evolution, La Trobe University, Melbourne, VIC 3086, \\ Australia; E-Mail: M.Steinbauer@latrobe.edu.au \\ 2 Department of Entomology, University of Wisconsin, Madison, WI 53706, USA; \\ E-Mail: guedot@wisc.edu \\ 3 Natural History Museum, London SW7 5BD, UK; E-Mail: d.percy@nhm.ac.uk \\ * Author to whom correspondence should be addressed; E-Mail: ulubanga@ @students.latrobe.edu.au.
}

Academic Editor: Brian T. Forschler

Received: 5 August 2015 / Accepted: 18 August 2015 / Published: 20 August 2015

The authors wish to make the following corrections to this paper [1]:

(1) Figure 3A, presented on page 586, shows a recording that at the time of publication was believed to be a duet between a male and female Aacanthocnema dobsoni (Hemiptera: Triozidae). This recording was made on a branchlet supporting a pair of psyllids which is why we believed it to be a duet. Recent recordings from isolated males are similar to recordings known to be duets. We now know that male calls comprise syllables of varying length and structure (including long-syllables and the short-syllables) while female calls comprise short-syllables only. The short-syllables produced by males are similar in structure to female syllables. We are convinced that Figure 3A in the original article does not represent a duet but rather a male call. Consequently we wish to make the following alterations to Figure $3 \mathrm{~A}$ which we hereby label 3A (i):

Replace the term duet with $\widehat{\jmath}$ call,

Remove the $\delta$ and $q$ symbols,

Remove the term reply latency (which applies only to duets).

In this correction, we show a typical male phrase Figure 3A (ii) and a typical female call Figure 3A (iii). 
Kindly replace:

A

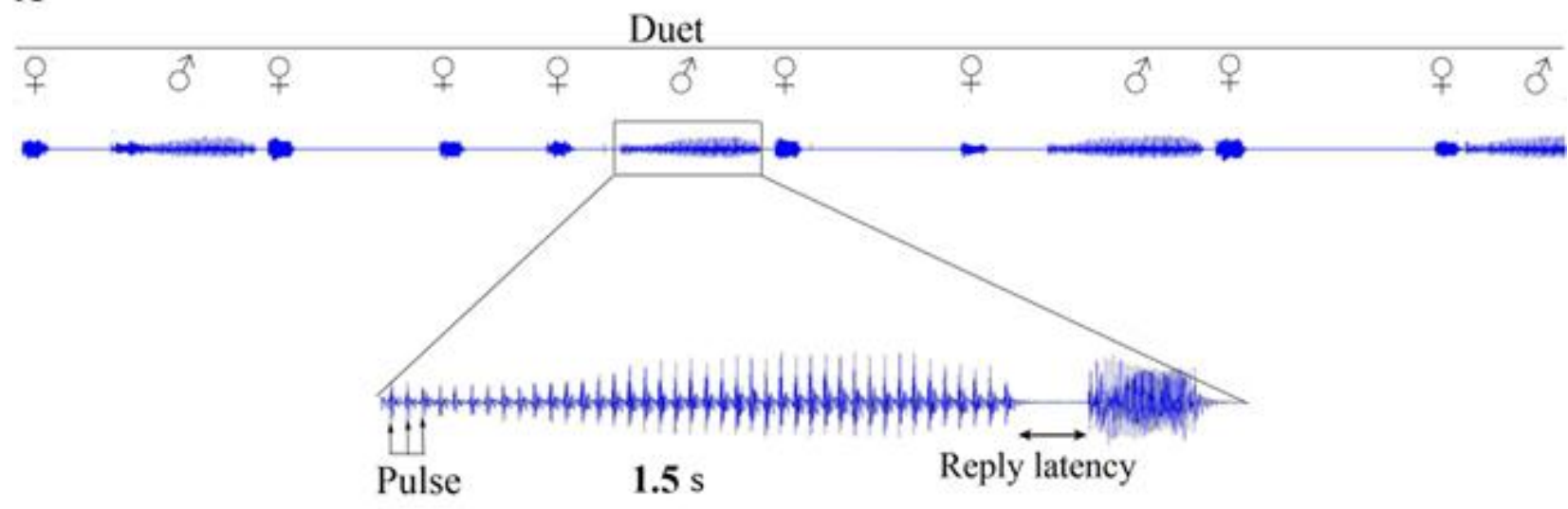

Call (syllable) length

with

A (i)

$\hat{\jmath}$ call

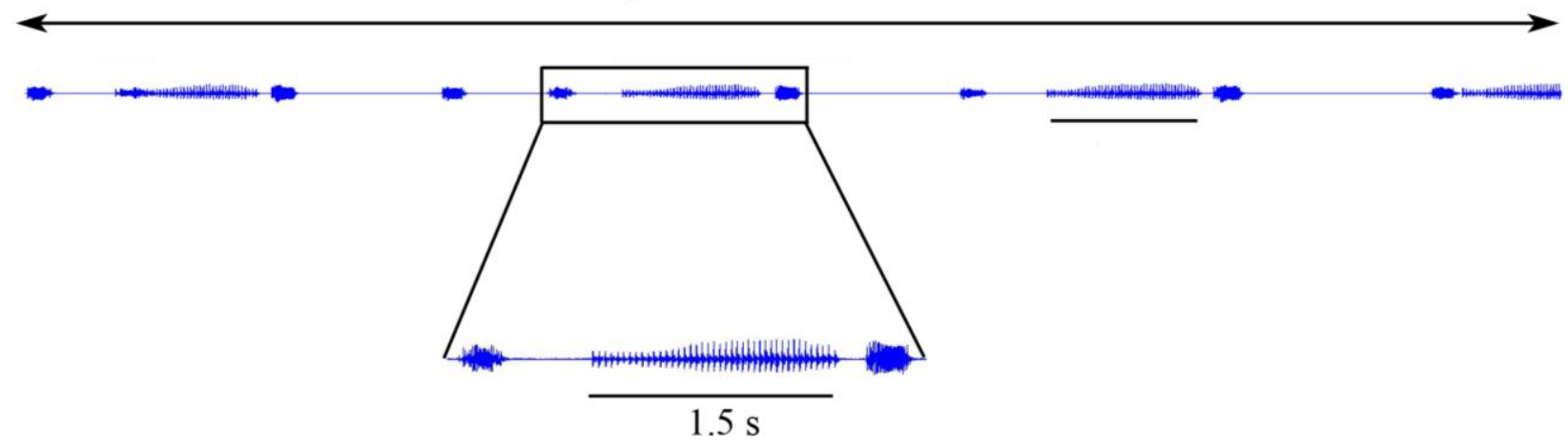

A(ii) ôphrase

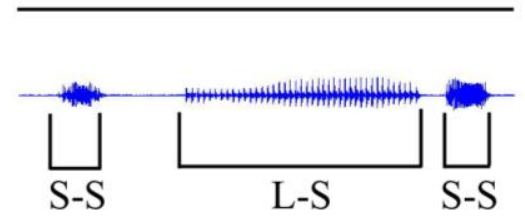

A(iii) $\quad$ c call

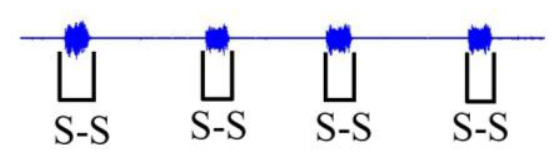

(2) Change to Figure 3 legend. Following the alterations listed above, the Figure 3 legend should be changed as follows:

From:

Vibrational duetting in triozid psyllids. (A) Aacanthocnema dobsoni; long, simple male call (syllable) and short female reply (syllable). (B) Schedotrioza apicobystra (published with permission from CSIRO publishing) short and complex, tightly synchronized male-female duet. $\mathrm{s}=$ seconds.

To:

Vibrational signalling in triozid psyllids. (A) (i) Aacanthocnema dobsoni, male call comprising multiple phrases; A (ii) typical male phrase comprising two short- and one long-syllable; A (iii) four short syllables comprising a female call. (B) Vibrational duet in Schedotrioza apicobystra (published 
with permission from CSIRO publishing) short and complex, tightly synchronized male-female duet. $\mathrm{s}=$ seconds, $\mathrm{L}-\mathrm{S}=$ long syllable, $\mathrm{S}-\mathrm{S}=$ short syllable .

The authors would like to apologize for any inconvenience caused to the readers by these changes.

\section{Reference}

1. Lubanga, U.K.; Guédot, C.; Percy D.M.; Steinbauer, M.J. Semiochemical and vibrational cues and signals mediating mate finding and courtship in Psylloidea (Hemiptera): A synthesis. Insects 2014, 5, 577-595.

(C) 2015 by the authors; licensee MDPI, Basel, Switzerland. This article is an open access article distributed under the terms and conditions of the Creative Commons Attribution license (http://creativecommons.org/licenses/by/4.0/). 